\title{
Observations of the Temporal Evolution and Spatial Structure of the Gap Flow in the Wipp Valley on 2 and 3 October 1999
}

\author{
MARTin D. WeISSMANN \\ Department of Meteorology and Geophysics, University of Innsbruck, Innsbruck, Austria, and Institute of Atmospheric Physics, \\ DLR, Oberpfaffenhofen, Wessling, Germany \\ G. J. MAYR \\ Department of Meteorology and Geophysics, University of Innsbruck, Innsbruck, Austria \\ R. M. BANTA \\ NOAA/Environmental Technology Laboratory, Boulder, Colorado
}

A. GoHM

Department of Meteorology and Geophysics, University of Innsbruck, Innsbruck, Austria

(Manuscript received 9 October 2003, in final form 19 May 2004)

\begin{abstract}
The investigation of gap flow in the Wipp Valley (GAP project) is one of the objectives of the Mesoscale Alpine Programme (MAP). The valley runs south-north across the Brenner Pass, from Italy to Austria. The pass is the lowest one of the main Alpine ridge and is therefore a favorable location for a gap flow, which is called foehn. Based on the extensive dataset of MAP, this study gives a detailed analysis of foehn on 2 and 3 October 1999 [intensive observation period 5 (IOP 5)]. The foehn event began as a gap flow that was separated from midlevel winds by a strong temperature inversion during the night of 1-2 October 1999. On the next night (23 October) the inversion dissipated, and the gap flow was combined with strong midlevel cross-ridge flow on 3 October 1999. This study shows that the existence of a temperature inversion above the gap flow has a crucial impact on the flow structure. Another emphasis of the study was the investigation of the small-scale flow structure downstream of the gap. Jumplike features and regions with flow reversals, which were interpreted as "rollers" (reversed rotors), could be observed in the Wipp Valley. A jet layer with a wavy structure indicated a gravity wave in the southern part of the valley. In the northern part the flow showed strong asymmetry with wind speeds nearly twice as strong on the eastern side as on the western one.
\end{abstract}

\section{Introduction}

This study provides an observational analysis of gap flow in the Wipp Valley on 2 and 3 October 1999 measured during the field campaign of the Mesoscale Alpine Programme (MAP) in fall 1999. One of the goals of MAP was the investigation of gap flow (foehn) in the Wipp Valley (GAP project). Foehn in the Wipp Valley is a pressure-driven flow through the gap of the Brenner Pass. The valley floor is not level as in many other gap flows (e.g., straits): it ascends upstream of the pass, and descends downstream of the pass (see section 1a). Therefore the flow is called foehn, which is "a wind

Corresponding author address: Martin Weissmann, Institut für Physik der Atmosphäre, Deutsches Zentrum für Luft- und Raumfahrt (DLR), Oberpfaffenhofen, D-82230 Wessling, Germany.

E-mail: martin.weissmann@dlr.de warmed and dried by descent ..."' (WMO 1992). However, the flow is driven by an along-gap pressure gradient, and primarily controlled by the Brenner Gap (Mayr et al. 2003).

The main objectives of GAP are to investigate the relative importance of gap width versus terrain height, the interaction of gap flow with midlevel winds, and the vertical and cross-gap distribution of wind speed and thermodynamic properties (Bougeault et al. 1998). The objectives of this study were to analyze 1) the temporal evolution of the foehn event of 2 through 3 October 1999, and 2) the small-scale flow structure in the Wipp Valley downstream of the gap. Emphases of the first objective were the synoptic conditions leading to gap flow, the transition from shallow to deep foehn, and the role of an inversion separating the gap flow from midlevel winds. The investigation of the small-scale flow structure focuses on the lateral asymmetry of the flow, 


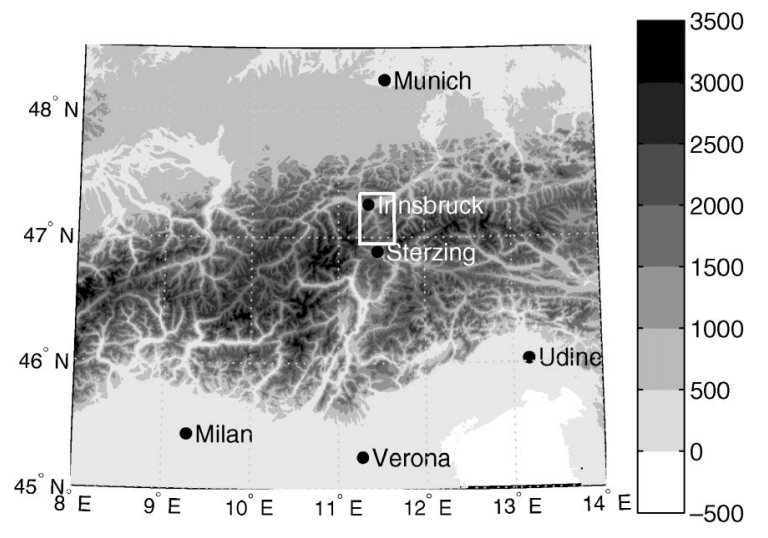

FIG. 1. Map of the central part of the Alps. The Wipp Valley region shown in Fig. 2 is indicated with a white rectangle. The grayscale bar shows the height of the topography in m MSL.

similarities to hydraulic studies (supercritical flow, jumplike features, rollers), and the differences between the gap flow on 2 October 1999 and gap flow combined with a midlevel cross-ridge flow on 3 October.

A large number of theoretical studies address flow over an obstacle (Long 1954; Houghton and Kasahara 1968; Smith 1985; Rotunno and Smolarkiewicz 1995), or through a lateral contraction (Wood 1968; Durran and Klemp 1987). But the Brenner Pass imposes both a lateral constriction and a vertical obstacle. A few studies deal with this more complex topic (e.g., Armi 1986; Pan and Smith 1999; Colle and Mass 1998a,b; Sprenger and Schär 2001; Drobinski et al. 2001). However, the topography of the Wipp Valley is far from being simple or symmetrical. Thus observational analyses of the flow structure are critical for a better understanding of foehn in the Wipp Valley. Comparisons with theoretical studies can be used for a qualitative interpretation of the small-scale flow features.

In recent years numerical models have been increasingly successful in simulating foehn events. In particular the results of Flamant et al. (2002), Gohm et al. (2004), and Zängl et al. (2004) are in many respects similar to the foehn structure observed on 2 and 3 October 1999. Flamant et al. (2002) describe a shallow foehn, and Gohm et al. (2004) and Zängl et al. (2004) describe a mostly deep foehn event. However, the temporal development of the foehn on 2 and 3 October 1999, which gradually evolves from a shallow to deep foehn, is different from other studies. For the first time, this time evolution and the structural differences between a shallow and deep foehn could be documented with a variety of measurements. The reversed rotor structure has been shown in simulations by Zängl et al. (2004), but has never been documented with observational data. And the causes for the flow asymmetry in the present study are different from the explanation given by Flamant et al. (2002).

Since models resolve spatial scales of about four grid increments or larger (Pielke 2002), a mesh size has to

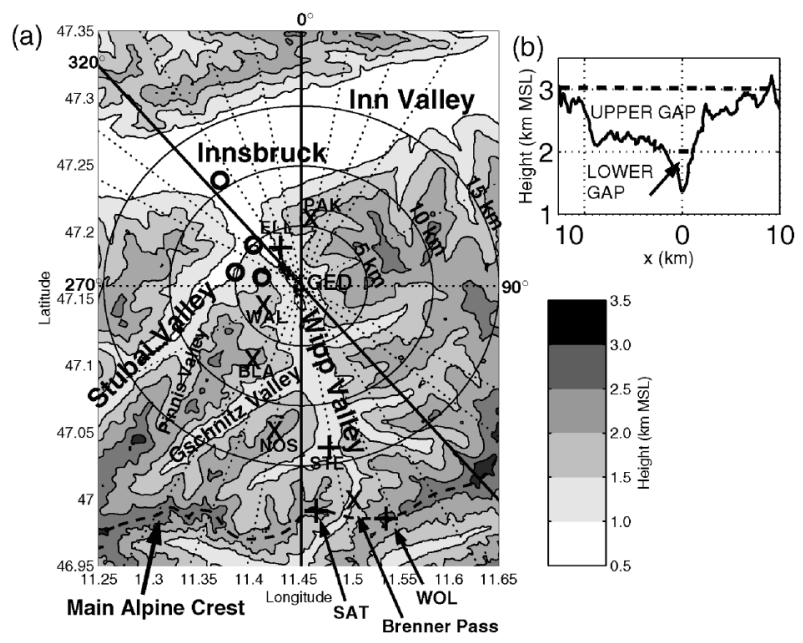

FIG. 2. (a) Map of the target area with the location of the lidar at Gedeir (GED; $1075 \mathrm{~m} \mathrm{MSL).} \mathrm{Circles} \mathrm{indicate} \mathrm{the} \mathrm{distances} \mathrm{of} \mathrm{5,} \mathrm{10,}$ and $15 \mathrm{~km}$ from the lidar; black lines show the two most common scan directions at an azimuth angle of $0^{\circ}$ and $320^{\circ}$. Black crosses indicate surface stations at Ellbögen (ELL; $1080 \mathrm{~m}$ MSL), Steinach (STE; 1116 m MSL), Sattelberg (SAT; 2108 m MSL), and Wolfendorn (WOL; $2777 \mathrm{~m}$ MSL). Black x's indicate relevant landmarks at Patscherkofel (PAK; 2247 m MSL), Waldrastjöchl (WAL; 1879 m MSL), Blaser (BLA; $2241 \mathrm{~m}$ MSL), Nösslachjoch (NOS; $2231 \mathrm{~m}$ MSL), and Brenner Pass (1371 m MSL). Four circles indicate the surface stations of Table 1: Gleins (1443 m MSL), MIE (1015 m MSL), SCH (990 m MSL), and NAT (811 m MSL) (from south to north, respectively). The main Alpine crest is indicated by a dashed line. Topography (m MSL) is shaded in 500-m intervals. (b) Height (km MSL) of the main Alpine crest from $11.34^{\circ}$ to $11.64^{\circ} \mathrm{E}$. The $x$ axis is the longitudinal distance from Brenner Pass in $\mathrm{km}$.

be on the order of $100 \mathrm{~m}$ to accommodate the complex topography of the Wipp Valley. Moreover, models still have problems with the simulation of the boundary layer (Farmer and Armi 2001) and sharp inversions, which are frequently observed between the gap flow and midlevel winds (Gohm et al. 2004).

This paper consists of five sections. The topography of the investigation area and the dataset used for the study are described in sections $1 \mathrm{a}$ and $1 \mathrm{~b}$. Section 2 gives a temporal overview of the whole foehn event of 2-3 October 1999. A detailed analysis of gap flow on 2 October is presented in section 3. The analysis of gap flow on 3 October, which was combined a with midlevel cross-ridge flow, follows in section 4. Finally, the conclusions of the study are given in section 5 .

\section{a. Topography}

The Wipp Valley (Wipptal) was the target area for gap flow investigations during the Special Observation Period (SOP) of MAP (Figs. 1 and 2). It is located in the eastern Alps between Sterzing, Italy, and Innsbruck, Austria, and runs across the Brenner Pass (1371 m MSL), which is the lowest pass of the main Alpine crest. The direction of the valley is roughly perpendicular to the main Alpine crest and therefore favorable for north 
and south foehn. Two major side valleys merge into the Wipp Valley from the southwest: The Gschnitz Valley (Gschnitztal) and the Stubai Valley (Stubaital). North of Brenner Pass the orientation of the valley is nearly south-north; in its lowest third [area of Gedeir (GED)] it turns slightly to the west.

The Brenner Pass (Brenner Gap) has a dual structure (Fig. 2) consisting of a narrow lower notch (lower gap), and a wide part between 2100 and $3000 \mathrm{~m}$ MSL (upper gap). The cross-sectional area of the upper gap is nearly 15 times larger than that of the lower notch. Thus most of the air usually flows through the upper gap (Mayr et al. 2004), and not through the lower notch during foehn (except during very shallow foehn events). Therefore the upper gap is the main control for the flow (Gohm and Mayr 2004).

To the north of the pass the valley is still fairly narrow until it widens north of Nösslachjoch (NOS), in the exit region of the Gschnitz Valley. Three mountain ridges protrude into the Wipp Valley downstream of the Brenner Pass. The summits embedded in these ridges are NOS (2231 m MSL), Blaser (BLA; $2241 \mathrm{~m}$ MSL), Waldrastjöchl (WAL; $1880 \mathrm{~m} \mathrm{MSL}$ ), and Patscherkofel (PAK; 2246 m MSL). At Innsbruck the Wipp Valley merges into the wide Inn Valley, which runs west-east. Southerly flow is deflected at a mountain ridge to the north of the Inn Valley (Nordkette), mostly into the lower (eastern) Inn Valley (Gohm and Mayr 2004).

\section{b. Data}

The backbone of this study is data from the scanning Transverse-Excited Atmospheric $\mathrm{CO}_{2}$ Doppler lidar (TEACO2; Post and Cupp 1990), operated by the National Oceanic and Atmospheric Administration's (NOAA's) Environmental Technology Laboratory (ETL). The instrument was situated at GED (1075 m MSL), about halfway between Brenner Pass and Innsbruck (Fig. 2). Its primary task was to collect a highresolution dataset of the three-dimensional flow structure in the Wipp Valley downstream of Brenner Pass. The lidar was operated from 0845 until 1840 UTC on 2 October, and from 0900 until 1400 UTC on 3 October. The maximum range of the lidar was about $15 \mathrm{~km}$ on 2 October 1999, and about $10 \mathrm{~km}$ on 3 October. The along-beam resolution was $300 \mathrm{~m}$. The lidar uses a pulsed laser at a wavelength of $10.59 \mu \mathrm{m}$. The Doppler frequency shift of the backscattered signal reveals the wind component along the lidar beam (radial velocity). Further information about the instrument and a comparison of aircraft in situ measurements and the lidar data collected at GED can be found in Durran et al. (2003).

This lidar has been used in several complex terrain studies (e.g., Banta et al. 1990, 1996, 1997, 1999), including downslope windstorm investigations in which hydraulic jump-like structures were revealed (Banta et al. 1990; Clark et al. 1994) and MAP studies of gap flow in the Wipp Valley (Flamant et al. 2002; Gohm and Mayr 2004; Gohm et al. 2004).

The present study makes use of the whole dataset of the 2 through 3 October 1999 foehn event. In addition to the lidar observations, in situ measurements from the NOAA P-3 aircraft along Wipp Valley transects are incorporated in the analysis, such as wind speed (including vertical motions), wind direction, temperature, and pressure. Thirty-five surface stations were installed throughout the area, all measuring wind speed, wind direction, temperature, and pressure. Rawinsondes were launched at Verona and Sterzing, Italy, and Innsbruck, Austria (Fig. 1). Mayr et al. (2003) describe the instrumentation in the Wipp Valley area during MAP SOP in more detail.

\section{Temporal overview}

The foehn event of 2 through 3 October began with fairly typical pre-foehn weather conditions. An upperlevel trough started to develop on 1 October to the north of the United Kingdom. Zonal upper-level winds prevailed in the Alpine region. Associated with the trough, a frontal system formed over the North Sea. Its warm front passed Germany on 1 October. The advection of warm air related to the warm front and a deepening of the trough led to a pressure fall north of the Alps. At the same time the pressure south of the Alps rose due to the eastward drift of a weak low pressure system centered at the Adriatic Sea. Hereupon a pressure gradient across the Alps with higher pressure to the south started to build up in the evening of 1 October. In contrast to the normal situation, there was no hydrostatic contribution to the south-north pressure gradient from warmer air to the north and colder air to the south of the Alps (Mayr et al. 2004). In fact rawinsonde data and the European Centre for Medium-Range Weather Forecasts (ECMWF) analysis showed slightly higher potential temperatures to the south of the Alps than to the north at the beginning of the foehn event (Weissmann 2003).

Southerly flow at the crest-top stations Sattelberg (SAT; $2108 \mathrm{~m} \mathrm{MSL)} \mathrm{and} \mathrm{Wolfendorn} \mathrm{(WOL;} 2777 \mathrm{~m}$ MSL) started at 2000 UTC 1 October. This onset of southerly flow can be seen as a sudden increase of wind speeds in Fig. 3. Foehn flow at Steinach (STE; $1116 \mathrm{~m}$ MSL) began at 0100 UTC 2 October, which is shown in Fig. 3 as a simultaneous increase of wind speed and potential temperature (the descent of air to the north of Brenner Pass during foehn events leads to an increase of potential temperatures). The onset of foehn was independently identified using vertical momentum fluxes (Lewis et al. 2004, manuscript submitted to Quart. J. Roy. Meteor. Soc.). Interestingly, the pressure difference between Bolzano, Italy $(60 \mathrm{~km}$ south of the main Alpine crest), and Innsbruck (35 km north of the main Alpine crest) was only $1 \mathrm{hPa}$ at that time [for the comparison the pressure was interpolated to the mean height of Bolzano and Innsbruck (410 m MSL)]. During the night of 


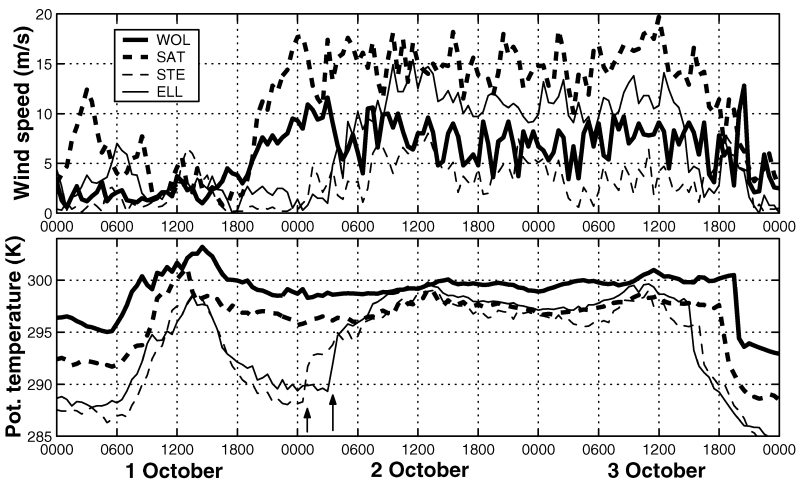

FIG. 3. (top) Wind speed and (bottom) potential temperature between 1 and 4 Oct at 0000 UTC at four different stations: SAT (2108 $\mathrm{m}$ MSL) and WOL (2777 $\mathrm{m} \mathrm{MSL}$ ) are mountain stations at the main Alpine crest, the station STE (1116 m MSL) represents the flow condition in the upper (southern) Wipp Valley, and ELL represents the flow condition (1080 m MSL) in the lower (northern) Wipp Valley. Arrows mark the beginning of gap flow at STE and ELL.

1-2 October the pressure difference between Bolzano and Innsbruck increased to $5 \mathrm{hPa}$, and foehn flow penetrated gradually into the lower Wipp Valley. At about 0330 UTC the foehn reached Ellbögen (ELL), and finally Innsbruck at 1030 UTC (Figs. 2 and 3). On 2 October the pressure trough over the Atlantic deepened and pushed farther south. This led to a turning of midlevel winds to west-southwesterly. The cold front associated with the trough passed northern France, but it did not reach the Alps. The pressure difference between Bolzano and Innsbruck stayed at $4-5 \mathrm{hPa}$. This led to a fairly steady foehn flow during the whole day. Only the depth of the foehn layer increased.

The foehn event began as a typical shallow foehn. This type of foehn is a southerly flow through the Brenner Gap, which does not extend above the main Alpine crest (Seibert 1990). Midlevel westerly winds and shal-

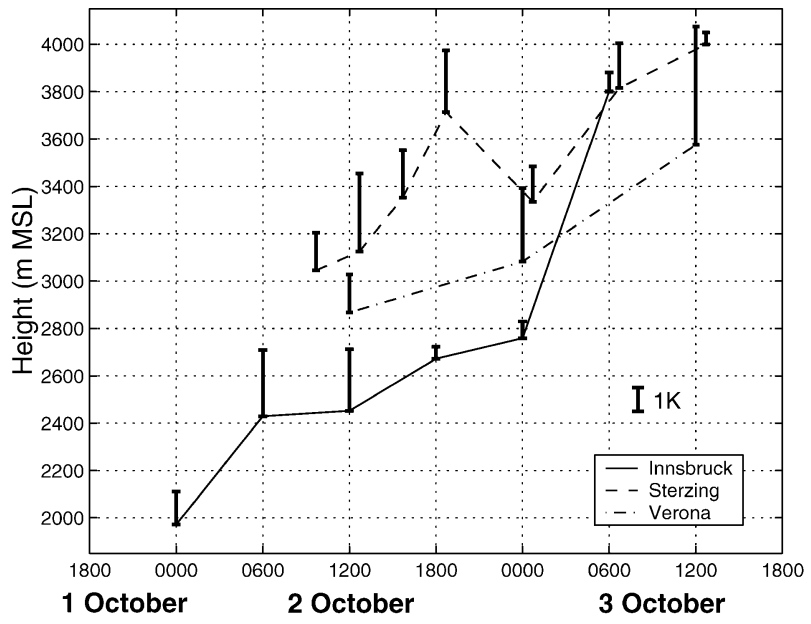

FIG. 4. Height of the lower boundary of temperature inversions between 1 and 3 Oct at 1800 UTC at Innsbruck, Sterzing, and Verona. The vertical bars are proportional to the temperature increase across the inversion. A reference bar in the right bottom shows the size of a temperature step of $1 \mathrm{~K}$.

low foehn flow are usually separated by a temperature inversion. At the onset of this foehn event the sounding close to the main Alpine crest at Sterzing (Fig. 4) showed an inversion at $3100 \mathrm{~m} \mathrm{MSL}$, below the average height of the main Alpine crest of about 3300 m MSL. This inversion was the upper boundary of southerly flow. On 2 October the inversion rose gradually to about $3700 \mathrm{~m} \mathrm{MSL}$ at $1800 \mathrm{UTC}$, and southerly winds extended above the main Alpine crest. Thus the foehn appeared to evolve from a shallow to a deep foehn in the afternoon. However, the flow structure was fairly steady throughout the day (Fig. 5), indicating that the evolution to a deep foehn was incomplete. In our view, the complete transition to a deep foehn occurred on 3
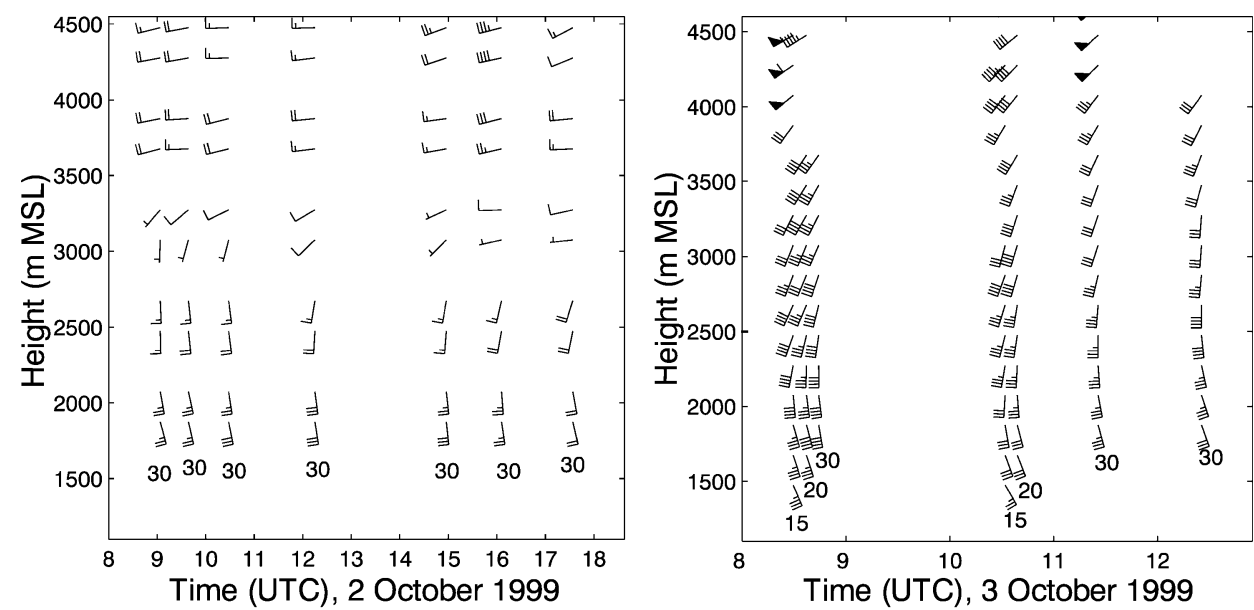

FIG. 5. Vertical wind profiles of the foehn flow at GED derived with the velocity-azimuth display (VAD) technique from conical lidar scans on (left) 2 Oct and (right) 3 Oct. The number beneath each profile indicates the elevation angle of the conical scan that was used to derive the wind profile. Half barbs, full barbs, and triangles indicate $2.5,5$, and $25 \mathrm{~m} \mathrm{~s}^{-1}$, respectively. The abscissa is the time in hours UTC. 

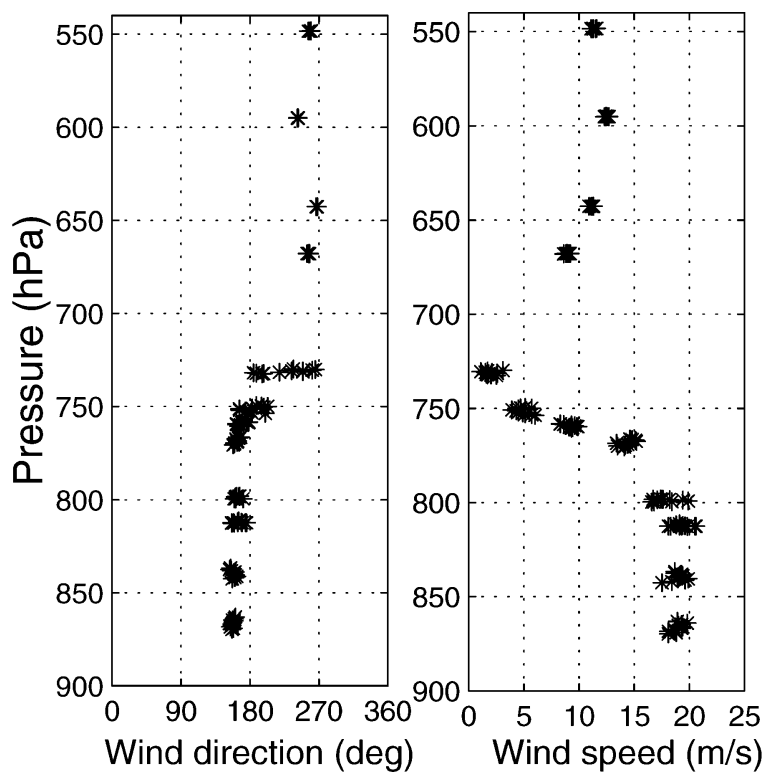

FIG. 6. Aircraft in situ measurements of (left) wind direction and (right) wind speed in the vincinity of GED. The data points were retrieved from several transects along the Wipp Valley on 2 Oct between 0937 and $1238 \mathrm{UTC}$ at a latitude within $47.17^{\circ} \mathrm{N} \pm 0.005^{\circ}$.

October, when the inversion dissipated and the foehn flow was combined with a midlevel cross-ridge flow.

During the night of 2 to 3 October a cold pool formed by nocturnal cooling and detached the foehn flow from the bottom of the Inn Valley. In the Wipp Valley foehn winds were observed throughout the night.

The approach of the trough continued during the night and into 3 October. This caused a turning of midlevel winds to southwesterly. Midlevel wind speeds increased from about $15 \mathrm{~m} \mathrm{~s}^{-1}$ on 2 October to $30 \mathrm{~m} \mathrm{~s}^{-1}$ on 3 October. On the morning of 3 October the cold front reached the Alps. This caused a pressure fall north of the Alps, and the pressure difference between Bolzano and Innsbruck increased to $6 \mathrm{hPa}$ at $1000 \mathrm{UTC}$. Afterward, the front passed the western Alps and a Genoa cyclogenesis took place. This resulted in a pressure fall south of the Alps, and a consequent decrease of the pressure gradient. The height of the temperature inversion at Sterzing decreased during the first half of the night to $3400 \mathrm{~m} \mathrm{MSL}$, and rose again to $3800 \mathrm{~m} \mathrm{MSL}$ during the second half (Fig. 4). Then the inversion dissipated on the morning of 3 October, and the gap flow on 3 October was combined with southwesterly midlevel winds (see section 4).

\section{Gap flow on 2 October}

\section{a. General flow structure}

During 2 October the depth of the southerly flow across the Brenner Gap increased from its onset in the early morning until the gap flow extended above the
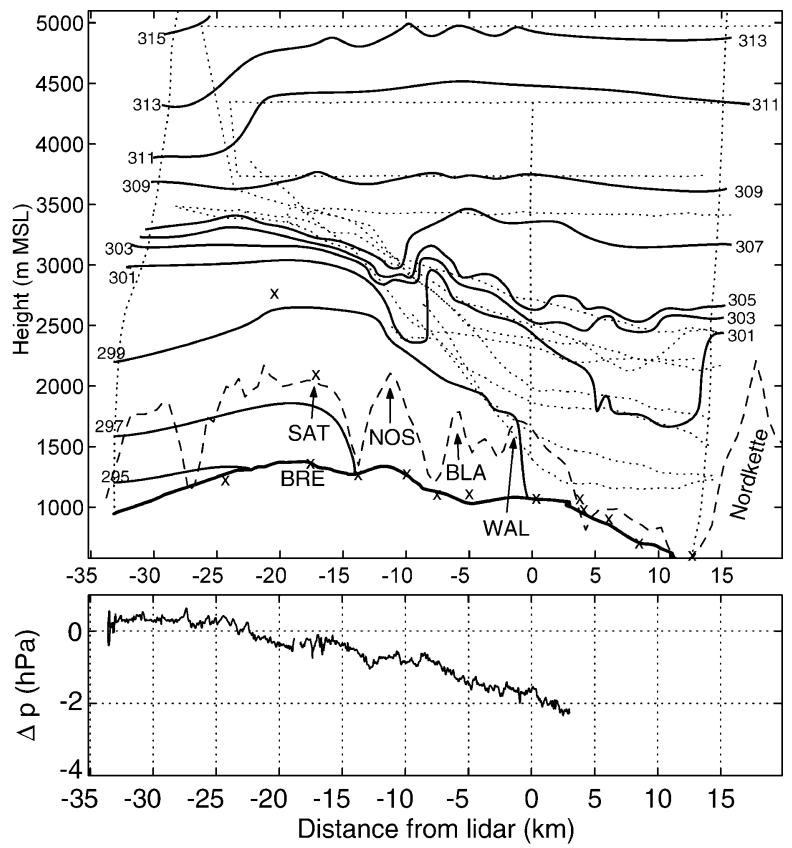

FIG. 7. (top) Hand analysis of a vertical cross section of potential temperature based on aircraft in situ measurements (dotted), rawinsondes (near-vertical dotted), surface stations $(X)$, and one synthetic vertical profile from aircraft data at GED (dotted). The flight operation lasted from 0937 to 1248 UTC 2 Oct, the surface station data are from 1130 UTC, and the rawinsonde data are from 1200 UTC. A thicker solid line shows the height of the bottom of the valley; a dashed line shows the average height of the topography within \pm 1 $\mathrm{km}$ from the center of the valley. The Brenner Pass (BRE) is located $18 \mathrm{~km}$ south of the lidar at GED. (bottom) Pressure difference at ground level along the autobahn relative to Sterzing. The pressure was reduced to a common altitude of 1336 m MSL (cf. Mayr et al. 2002).

main Alpine crest by late afternoon. Thus the flow structure changed from a shallow to a deep foehn. The general flow structure was fairly steady through the day, however. The foehn was vertically bounded by a strong inversion, which separated southerly foehn flow from west-southwesterly winds aloft (Fig. 4). The comparison of aircraft in situ measurements, rawinsonde, and lidar data showed good agreement between this inversion and a distinct shear layer between southerly foehn flow and west-southwesterly winds aloft (Figs. 4-7). As shown in Fig. 5, the location of the shear layer at GED, and its vertical extension changed little throughout the day. The gap flow intensity fluctuated by up to $5 \mathrm{~m} \mathrm{~s}^{-1}$. However, the general structure and all the flow features described in this section were consistent through the day.

Upstream of the main Alpine crest the inversion rose about 200-300 m between Verona at the southern rim of the Alps and Sterzing close to the main crest (Fig. 4). To the north of the main crest the inversion height decreased 600-1000 $\mathrm{m}$ toward Innsbruck. The average foehn air mass descended up to $2000 \mathrm{~m}$ to the north of the main Alpine crest (see, e.g., the 299-K isentrope in 


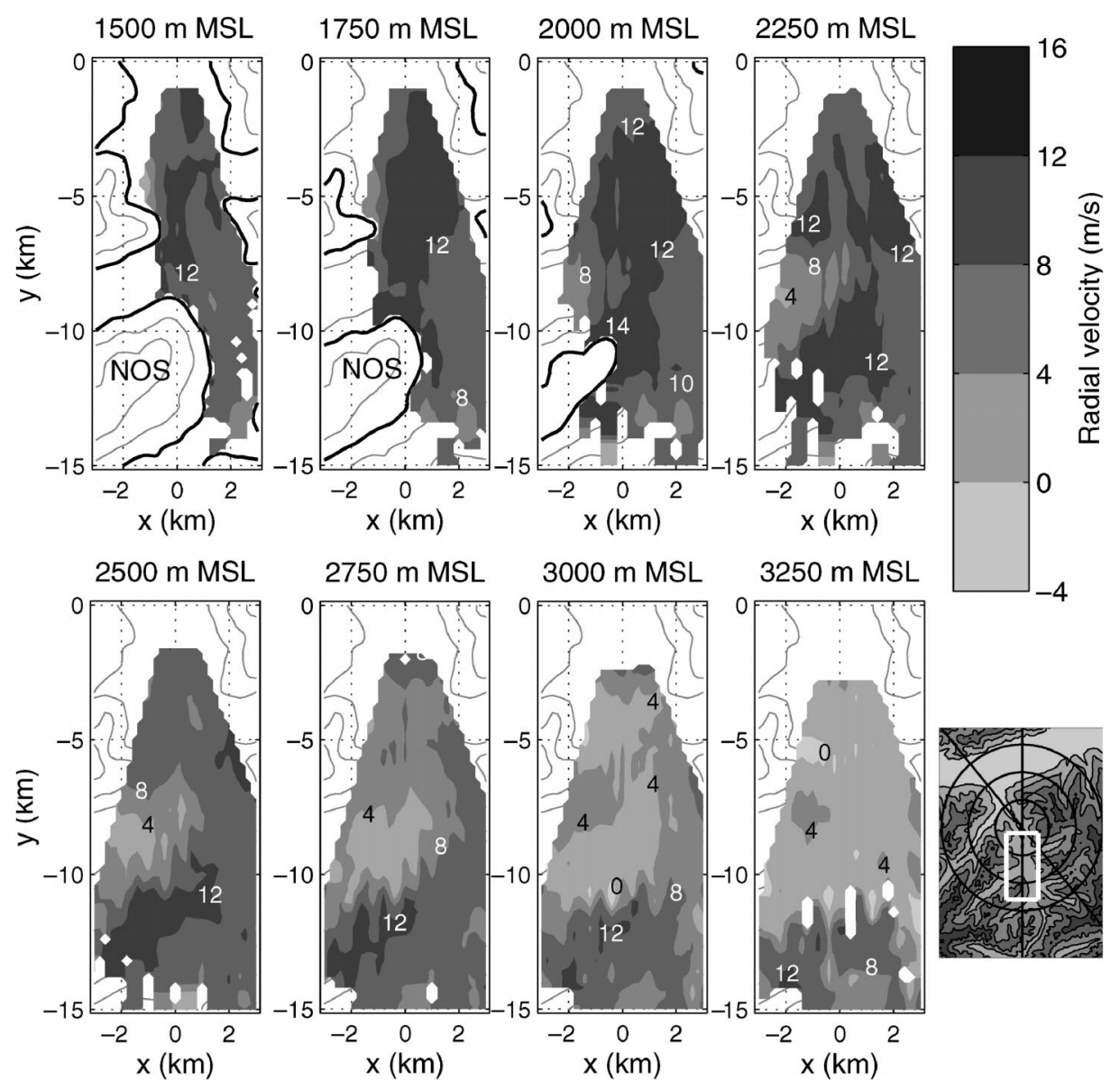

FIG. 8. Horizontal cross sections of radial velocity derived from a set of conical lidar scans at different elevation angles (volume scans) taken at 1443 UTC 2 Oct. The location of the cross sections is shown with a white rectangle on the small map.

Fig. 7). The upper boundary of the foehn flow at the main Alpine crest was seen at $3100 \mathrm{~m}$ MSL in the morning, and rose to $3800 \mathrm{~m} \mathrm{MSL}$ in the evening (Fig. 4). Farther north in the Wipp Valley, at GED, the upper boundary was seen around $3000 \mathrm{~m}$ MSL throughout the day (Fig. 5). As described in section 1, the Brenner Gap has a dual structure with a narrow lower notch and a wide upper gap above $2000 \mathrm{~m}$ MSL. One of the early findings of MAP was that most of the foehn air usually flows through the upper gap, whereas the lower gap plays a relatively minor role (Mayr et al. 2003, 2004). The analysis of the foehn on 2 October reinforces this notion. The cross-sectional area of the upper gap is nearly 15 times larger than the area of the lower gap. Wind speeds in the lower gap measured by a sodar close to Brenner Pass were only 6-12 $\mathrm{m} \mathrm{s}^{-1}$ (Weissmann 2003). The wind speeds at the crest-top stations were 12-18 $\mathrm{m} \mathrm{s}^{-1}$ at SAT (2108 m MSL) and 5-10 $\mathrm{m} \mathrm{s}^{-1}$ at WOL (2777 m MSL) (Fig. 3). Therefore, if we assume uniform flow across the cross section, only about $5 \%$ of the foehn air flowed through the lower gap, and 95\% flowed through the upper gap.
The potential temperatures measured at surface stations in the valley (e.g., at ELL) were higher than the temperatures at SAT, which indicates that the average air mass originated at levels higher than SAT (Fig. 3). This descent of air from the upper gap is also illustrated in the cross section of potential temperatures (Fig. 7).

The horizontal range of the Doppler lidar at GED was not large enough to measure the wind speeds at the Brenner Gap. Lidar measurements started about $5 \mathrm{~km}$ north of the Brenner Pass. Three-four kilometers north of Brenner Pass, the Wipp Valley widens and a part of the air mass from the upper gap descends into the valley (inferred from potential temperatures, as described). But most of the air stays elevated, flows over the ridge of NOS, and descends to its lee. Doppler lidar scan data (Fig. 8) show that maximum winds are observed above NOS and not in the narrow valley east of the mountain. To the lee of the mountain the increase of wind speeds at lower levels and the decrease of velocities at upper levels shows the large descent of air.

A 500-m-deep jet layer formed as the air accelerated down the lee slope of NOS (Fig. 9). This layer flowed 

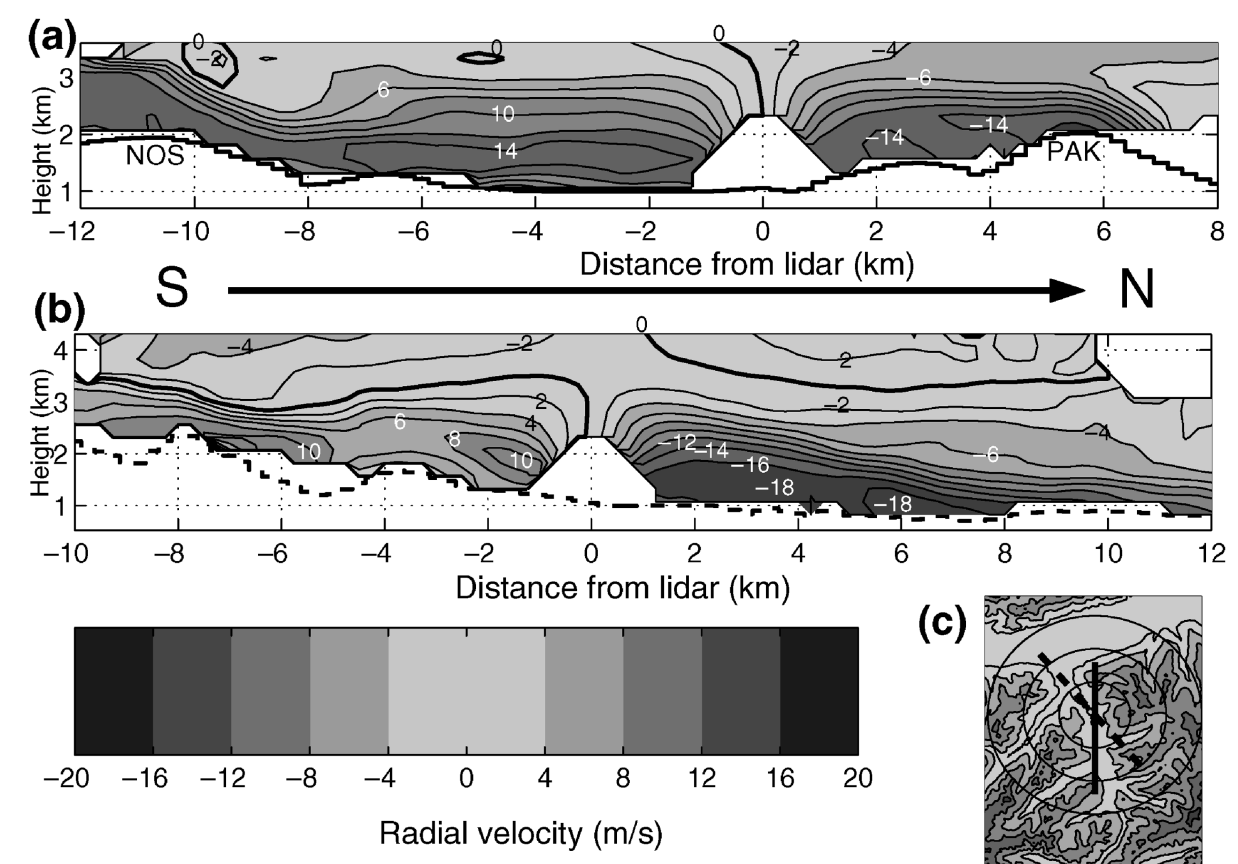

(c)

FIG. 9. Two vertical cross sections of radial velocity, each averaged over four vertical-slice lidar scans. The scans were taken at 1059 UTC 2 Oct at an azimuth of (a) $0^{\circ}$ and (b) $320^{\circ}$. (c) The baseline of the scans is shown with (a) a solid black line and (b) a dashed black line. Scan (a) shows the flow in the center of the valley to the south of GED, and scan (b) shows the flow in the center of the valley to the north of GED. An arrow indicates the major direction of foehn flow. Positive radial velocities are flow toward the lidar, and negative velocities are flow away from the lidar. A thick line indicates the zero contour line of radial velocity.

through the southern part of the valley as an elevated jet ( $\sim 500 \mathrm{~m} \mathrm{AGL})$, and descended to the ground, as it passed over GED. The cross sections (Fig. 10) show a hydraulic jump downstream from NOS both in the isentropes and the pressure distribution.

Maximum wind speeds on this day were about 22 $\mathrm{m} \mathrm{s}^{-1}$, and lidar scans showed an increase of wind speed of nearly $5 \mathrm{~m} \mathrm{~s}^{-1}$ from the southern to the northern part of the valley.

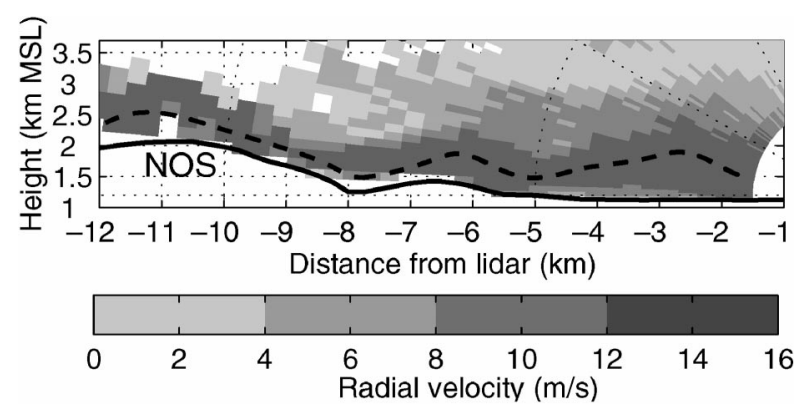

FIG. 10. Vertical slice lidar scan of radial velocity. The scan was taken at 1105 UTC 2 Oct at an azimuth of $180^{\circ}$. The abscissa is the distance from the lidar at GED in $\mathrm{km}$. The surface elevation is shown by a solid black line. The direction of the flow is from left to right. A dashed line marks the center of the jet.

\section{b. Flow over Nösslachjoch, Patscherkofel, and Blaser}

As described in section 1a mountain ridges protrude into the Wipp Valley from east and west, and foehn air has to flow over several obstacles. In particular the flow over NOS was well documented by the Doppler lidar at GED and aircraft in situ measurements. The structure is similar to the flow configuration used in two-dimensional theoretical studies (Armi 1986; Smith 1985; Durran and Klemp 1987) and obtained from experiments in hydraulic channels (Pawlak and Armi 1998). Of course the topography in this area is not at all twodimensional, so that three-dimensional effects also need to be considered. But these studies seem suitable for a qualitative interpretation of the flow structure.

The flow over NOS was interpreted as shown in Fig. 11:

1) A thinning and descending of the foehn flow was observed to the lee of the mountain, which resembles "supercritical flow" or "shooting flow" to the lee of an obstacle. This can be seen as a descent of isotachs to the lee of NOS 8-11 km south of GED (Figs. 9a and 10), and as a descent of isentropes on Fig. 7.

2) Farther downstream (7-9 km south of GED) a sudden deepening of the foehn layer was observed, 


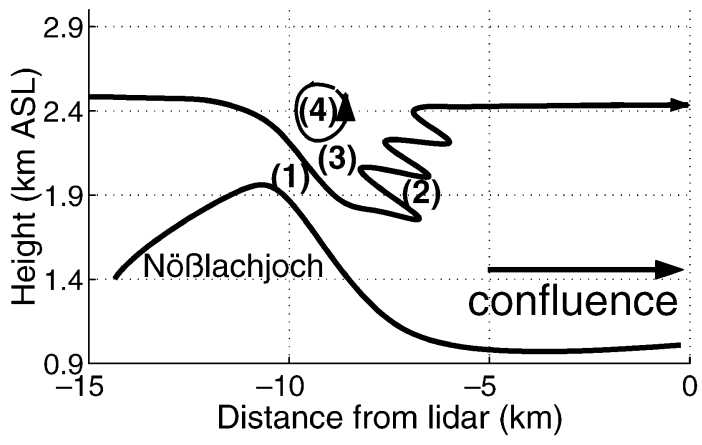

FIG. 11. Sketch of the flow over Nösslachjoch derived from Doppler lidar data (Figs. 8, 9, 10, and 12), and aircraft in situ measurements (Fig. 7). The numbers indicate the flow features discussed in the text: 1) supercritical (shooting) flow; 2) hydraulic jump; 3) region with very weak winds; 4) roller or reversed rotor. Farther downstream of Nösslachjoch ( $5 \mathrm{~km}$ south of the lidar), two branches of the flow merge to one, which leads to horizontal confluence and increased low-level wind speeds.

which was interpreted as a hydraulic jump-like feature. This is indicated by a rise of isotachs on the lidar scans (Figs. 9a and 10), and as a rise of isentropes on the cross section of potential temperature (Fig. 7). Aircraft in situ measurements in this region showed strong vertical motions of -4 to $+6 \mathrm{~m} \mathrm{~s}^{-1}$ (Weissmann 2003), which is further evidence of hydraulic-jump behavior. At first glance, the low-level wind speeds downstream of the jump seem to contradict the transition from super- to subcritical flow in a hydraulic jump as described by one-dimensional hydraulic theory. In the present case, however, threedimensional effects modify this classical one-dimensional pattern. The increase of low-level wind speeds can be explained by horizontal confluence due to a narrowing of the valley (a mountain ridge protrudes into the Wipp Valley as described in section 1a).

3) A region with low velocities was observed above the descending jet layer to the lee of NOS, 7-9 km south of GED (Figs. 8 and 9a). The stagnation zone formed above the shooting, supercritical flow beneath. Unfortunately we do not have data to trace its formation to contribute to the ongoing debate about mechanisms for the formation (small-scale instabilities and flow separation versus wave breaking) of such a stagnation zone (Farmer and Armi 1999, 2001; Afanasyev and Peltier 2001a,b; Cummins 2000).

Also three-dimensional effects need to be considered. The Gschnitz Valley merges into the Wipp Valley from the west in the same region. An outflow of the Gschnitz Valley would push the foehn flow eastward, causing a reduction of southerly wind component. However, a deflection of foehn would result in higher wind speeds in the eastern part of the valley, which were not observed in volume lidar scans

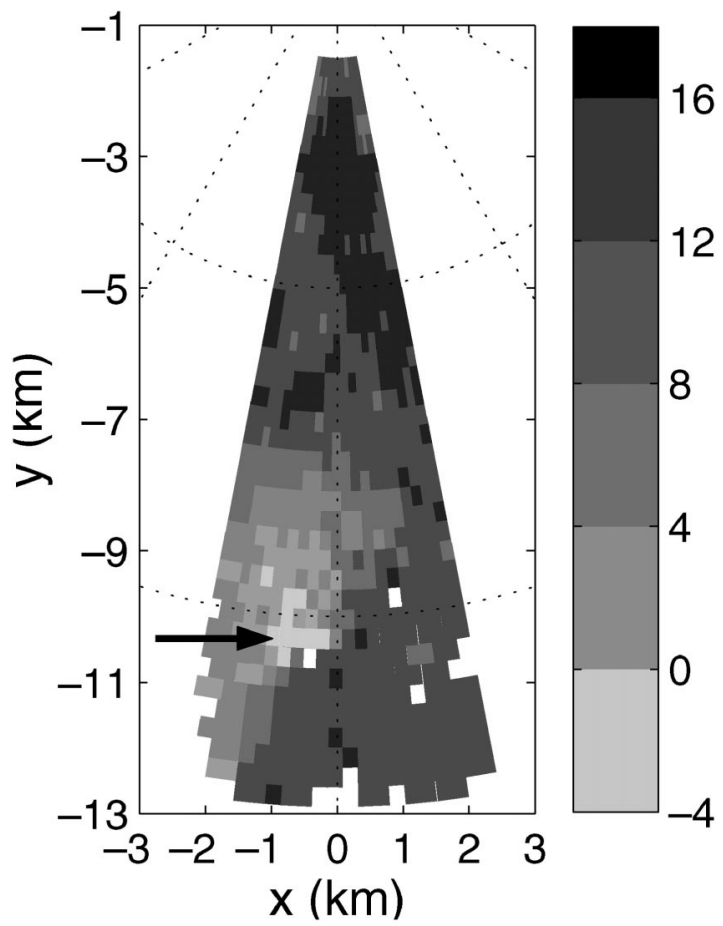

FIG. 12. Southern part of a conical lidar sector scan of radial velocity at an elevation angle of $8^{\circ}$ taken at 1133 UTC 2 Oct. The lidar site (GED) is at $(x, y)=(0,0)$. The direction of foehn flow is from bottom to top. A region with slightly negative velocities indicating northerly winds (marked by an arrow) was observed at about $10 \mathrm{~km}$ south of GED, which is surrounded by southerly winds of up to 16 $\mathrm{m} \mathrm{s}^{-1}$.

(Fig. 8). This suggests that the outflow of the Gschnitz Valley does not play a significant role.

This region with flow stagnation has also been documented on other days with shallow foehn (Flamant et al. 2002; Gohm and Mayr 2004). But it was not seen during deep foehn events as on 3 or 24 October 1999 (Gohm et al. 2004). The important difference seems to be the absence of a near-crestlevel inversion in the deep foehn events, which is crucial for the formation of a wave-breaking region (Gohm and Mayr 2004; Klemp and Lilly 1975).

4) On some scans also a small region with negative radial velocities, indicating flow reversal, was seen to the lee of NOS above the descending jet layer (Fig. 12). This flow reversal was interpreted as a roller ("reversed rotor"), which is frequently observed in hydraulic experiments (e.g., Rouse et al. 1959), and was also shown in theoretical studies (Rotunno and Smolarkiewicz 1995).

A similar, and even stronger flow reversal with northerly winds of more than $4 \mathrm{~m} \mathrm{~s}^{-1}$ was seen to the lee of PAK (Fig. 13). This reversal was also interpreted as a reversed rotor. The frequent observation of rotor clouds to the lee of PAK during strong foehn events supports this interpretation. Furthermore, aircraft in situ measurements during foehn 

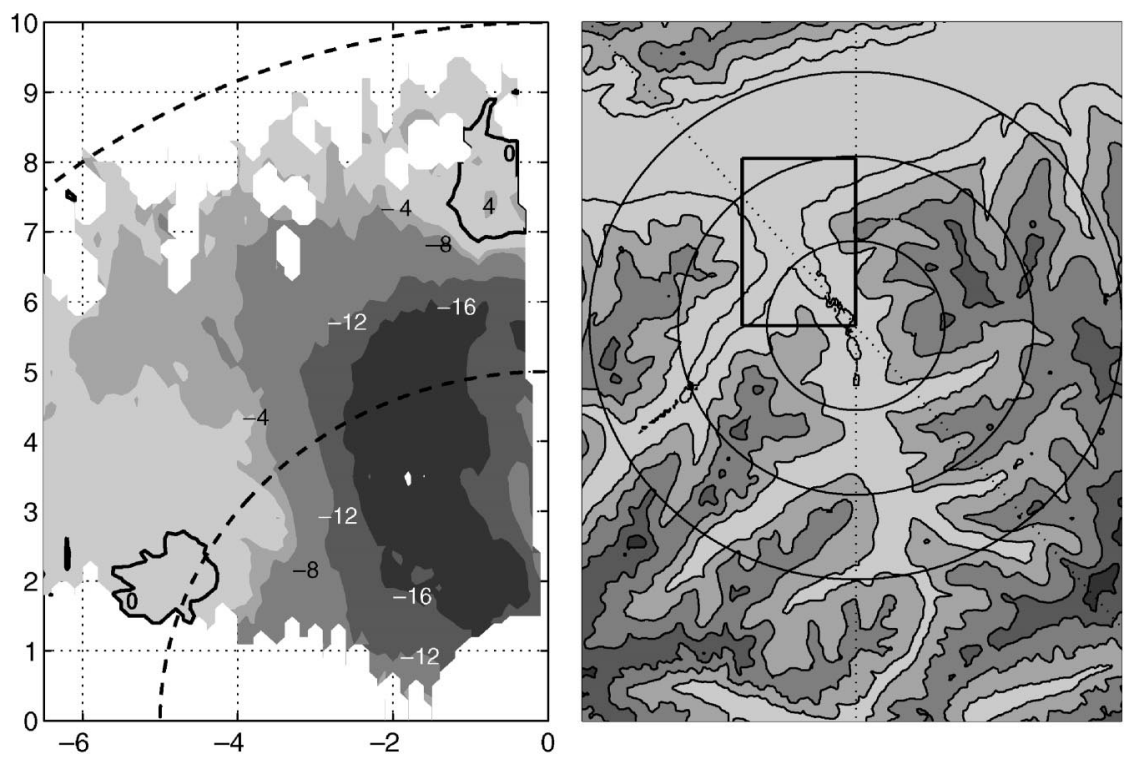

FIG. 13. Northern part of a conical lidar scan of radial velocity at an elevation of $10^{\circ}$ taken at 1226 UTC 2 Oct. The location of the scan is shown on a map to the right. Dashed rings (left) indicate the distances of 5 and $10 \mathrm{~km}$ from the lidar, which equal a height of $1950 \mathrm{~m}$ MSL and $2800 \mathrm{~m}$ MSL. A solid black line indicates the zero contour line of radial velocity. The direction of foehn flow is from bottom to top. A region with positive velocities up to $4 \mathrm{~m} \mathrm{~s}^{-1}$ indicating northerly flow is seen $7.5 \mathrm{~km}$ north of the lidar, although the flow is generally southerly (bottom to top).

have shown strong vertical motions of $\pm 5 \mathrm{~m} \mathrm{~s}^{-1}$ to the lee of PAK (Malcher 2001). Simulations with a hydraulic model and observations with an aerosol lidar have shown a hydraulic jump at that location on 20 October 1999 (Gohm and Mayr 2004). And also simulations by Zängl et al. (2004) using the fifth-generation Pennsylvania State University-National Center for Atmospheric Research (PSUNCAR) Mesoscale Model (MM5) simulating intensive observation period (IOP) 10 have shown a reversed rotor structure there.

Lidar scans also indicate the existence of a reversed rotor to the lee of BLA (Weissmann 2003), but it was not as clear as to the lee of NOS and PAK.

\section{c. Asymmetry of the foehn flow}

To the north of GED the foehn flow was nearly twice as strong in the eastern part of the valley as in the western part (Fig. 14). A similar structure was observed during several other foehn events of the MAP SOP (Mayr et al. 2003; Flamant et al. 2002; Gohm and Mayr 2004). This asymmetry seems to be caused by two phenomena:

1) The direction of the Wipp Valley and the direction of foehn flow upstream of GED is from south to north (Fig. 2). At GED the valley turns slightly to the west. The southerly flow, however, keeps its direction because of its inertia.

2) A small mountain (WAL, $1880 \mathrm{~m}$ MSL; Fig. 2) em- bedded in a lateral ridge to the west of the Wipp Valley, close to GED, plays a role in this asymmetry as well. This obstacle in the western part of the valley drops rapidly to its lee, favoring strong downslope winds with a likely transition to supercritical flow. We hypothesize that a hydraulic jump occurs at the downstream base of WAL. We infer these flow features from surface pressure measurements (Table 1). The pressure at the bottom of WAL [at Mieders (MIE) and Schönberg (SCH)], that is, in the jump, was approximately equal to the pressure at WAL itself. Farther downstream it dropped again by about $0.2 \mathrm{hPa}$ at Natters (NAT) and the subcritical flow then decelerates further as the valley widens to the west. In the eastern part of the valley the flow rather accelerates (Fig. 14). This hydraulic jump was also show in simulations with a hydraulic model for 20 October 1999 (Gohm and Mayr 2004).

Flamant et al. (2002) explained the asymmetry on 30 October 1999 with the descent of geostrophic winds to the lee of a high mountain range southwest of this region, which was seen in numerical simulations. These descending winds caused an outflow of the Stubai Valley, which pushed the foehn eastward. However, the Doppler lidar, aircraft in situ measurements, and the surface stations did not document any outflow of the Stubai Valley on 2 October below $1800 \mathrm{~m}$ MSL. At levels above $1800 \mathrm{~m}$ MSL indication of a weak outflow can be seen in the lidar data (Fig. 14). However, the outflow on 2 October was too weak to cause such a 

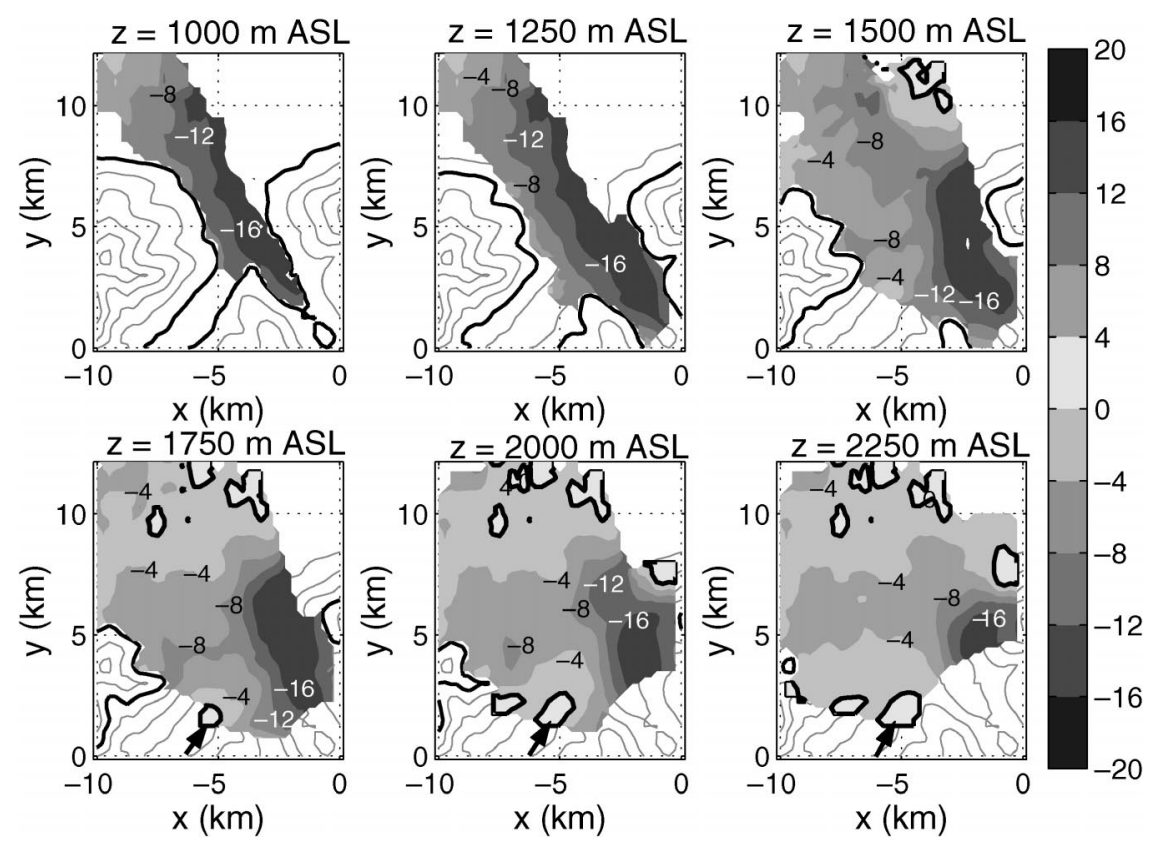

FIG. 14. Horizontal cross sections of radial velocity derived from a set of conical lidar scans at different elevation angles (volume scans) taken at 1226 UTC 2 Oct. The Doppler lidar is located on the lower-right corner of each panel at $(x, y)=(0,0)$. Abscissa and ordinate are the distance from the lidar site (GED). The main direction of the foehn flow is from the bottom to the top of every cross section (south-north). Negative velocities are flow away from the lidar; positive velocities are flow toward the lidar. A solid black line indicates the zero contour line of radial velocity. A region with very low positive radial velocities indicating an outflow of the Stubai Valley is marked with arrows.

strong asymmetry. The descent of midlevel winds and the resulting outflow may be more important during foehn events that are combined with strong southwesterly midlevel winds.

The Coriolis force is seen to be negligible, because the typical Rossby numbers of foehn flow are between 3 and $7[$ Ro $=U /(L f)$, where Ro is the Rossby number, $f$ the Coriolis parameter, $L$ the length scale $(30 \mathrm{~km})$, and $U$ the velocity scale $\left.\left(10-20 \mathrm{~m} \mathrm{~s}^{-1}\right)\right]$.

\section{d. Temporal variability}

The general flow structure described in the previous sections was observed throughout the day. Nevertheless there was some temporal variability of the flow. Despite the rise of the inversion of $700 \mathrm{~m}$ at Sterzing during

TABLE 1. Average of surface pressure difference between 1000 and 1600 UTC of 2 Oct 1999 at stations along the western part of the lower Wipp Valley, relative to the station Gleins (1443 m MSL) at the WAL ridge. For comparison the pressure was reduced to a common height of $1015 \mathrm{~m}$ MSL. MIE is a station directly to the lee of WAL; SCH is also to the lee of WAL, but closer to the center of the Wipp Valley; and NAT is located farther downstream (Fig. 2).

\begin{tabular}{cccc}
\hline \hline & MIE & SCH & NAT \\
& $(1015 \mathrm{~m} \mathrm{MSL})$ & $(990 \mathrm{~m} \mathrm{MSL})$ & $(811 \mathrm{~m} \mathrm{MSL})$ \\
\hline$\Delta p(\mathrm{hPa})$ & -0.05 & 0.13 & -0.20 \\
\hline
\end{tabular}

the day (Fig. 4), the depth of foehn flow downstream of the gap did not increase significantly (Fig. 15). The two southernmost cross sections show a slight rising tendency (Figs. 15a and 15b), but the depth of the flow at the other four cross sections was similar throughout the day (Figs. 15c-f). Maximum velocities varied between 12 and $18 \mathrm{~m} \mathrm{~s}^{-1}$ to the south of the lidar, and between 14 and $22 \mathrm{~m} \mathrm{~s}^{-1}$ to the north of the lidar.

The flow within the valley (Figs. 15b, 15d, and 15e) showed the highest wind speeds between 1000 and 1300 UTC, whereas the strongest flow over NOS (Fig. 15a) and PAK (Fig. 15f) occurred between 1200 and 1400 UTC. The flow a few kilometers south of GED (Fig. $15 \mathrm{c})$ shows both maxima, because the flow over NOS, and the flow within the narrow valley merge horizontally at that point. A rise of the inversion at Sterzing (Fig. 4) is seen as the cause for this difference of maximum winds. Presumably the higher inversion in the early afternoon caused a stronger flow through the upper gap, which led to a stronger flow over NOS and PAK, and to a rise of the jet layer south of GED (Fig. 15c).

A midlevel wind maximum passed the Alpine region between 1545 and 1700 UTC (Fig. 5). At the same time the flow over NOS (Fig. 15a) and the flow in the eastern part of the valley downstream of GED (Fig. 15e) showed a clear minimum. The flow over PAK (Fig. 15f) in contrast, showed a weak relative maximum. Therefore it 

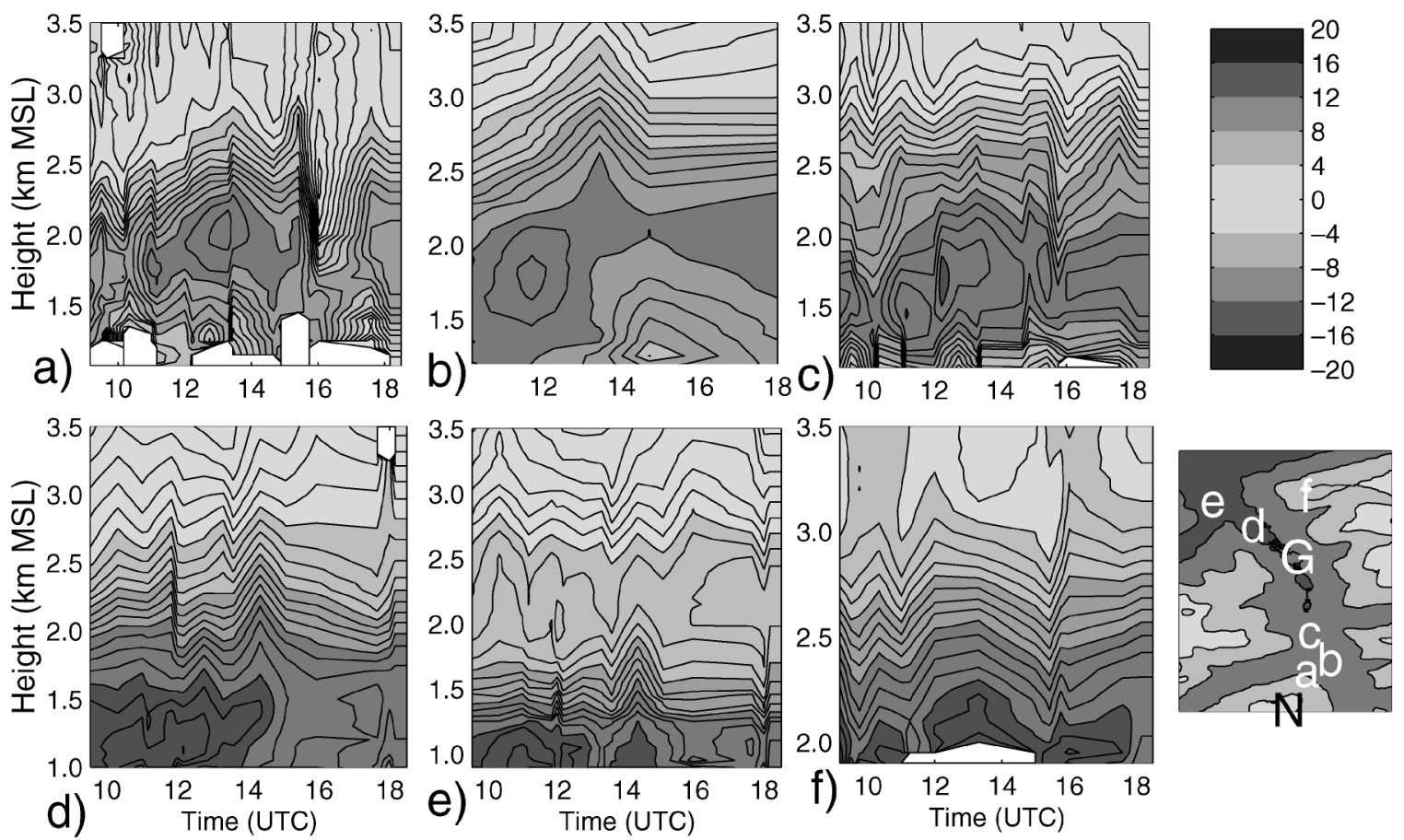

FIG. 15. Time-height cross sections of radial velocity measured with Doppler lidar at GED. The $x$ axis is the time in hours (UTC); the $y$ axis is the height ( $\mathrm{km} \mathrm{MSL}$ ). The radial velocity $\left(\mathrm{m} \mathrm{s}^{-1}\right)$ is shaded (see grayshade bar to the right). The locations of the profiles are shown in the small map to the right. (a) The flow to the lee of NOS, (b) the flow in the center of the valley east of NOS, (c) the flow in the valley $5 \mathrm{~km}$ upstream of GED, (d) the flow $4 \mathrm{~km}$ downstream of GED, (e) the flow $7 \mathrm{~km}$ downstream, and (f) the flow over PAK. The map covers the area from $47.055^{\circ}$ to $47.24^{\circ} \mathrm{N}$ and $11.375^{\circ}$ to $11.505^{\circ} \mathrm{E}$. Nösslachjoch (NOS) is marked with $\mathrm{N}$ on the map, Gedeir (GED) with G, and the locations of (a)-(f) are marked.

seems that this midlevel maximum caused a weaker gap flow and a stronger asymmetry of the flow downstream of GED. The reason for this interaction of midlevel winds and gap flow is presumably a descent of midlevel winds to the lee of high mountains west of the Wipp Valley as described by Flamant et al. (2002). The details for this interaction, however, remain unclear.

\section{Gap flow combined with a midlevel cross-ridge flow on 3 October}

\section{a. General flow structure}

The foehn on 3 October showed the typical characteristics of a deep foehn. The cross-barrier flow extended above the main Alpine crest (midlevel cross-ridge flow of about $30 \mathrm{~m} \mathrm{~s}^{-1}$ ). Underneath, a gap jet emanated from the incision at Brenner Pass similar to the idealized settings in Pan and Smith (1999). The temperature inversion weakened during the evening of 2 October and finally disappeared in the morning of 3 October (Fig. 4). As a consequence there was no distinct shear layer, and winds turned gradually with height from a southerly foehn flow to southwesterly winds aloft (Fig. 5).

The flow structure was different from the previous day. A jet layer was seen between 2500 and $3500 \mathrm{~m}$ MSL, about $1 \mathrm{~km}$ higher than on 2 October (Fig. 16a). A small fraction of the air descended to the ground, as it passed GED. But most of the air passed through the Wipp Valley as an elevated jet, and flowed over PAK in the northern part of the valley. In contrast to 2 October, the flow over NOS on 3 October did not show the features discussed in section $3 \mathrm{~b}$ (shooting flow, flow stagnation, reversed rotor). The lidar scans showed that wind speeds downstream of GED were much stronger above PAK (Fig. 16a) than in the center of the valley (Fig. 16b). Compared to 2 October, wind speeds in the lidar scans of up to $25 \mathrm{~m} \mathrm{~s}^{-1}$ were a few meters per second higher than on the previous day, but wind speeds at the surface stations were slightly lower (Fig. 3). This was explained by the fact that the jet layer did not descend to the bottom of the valley as on the previous day. The descent of air to the north of Brenner Pass was slightly stronger on 2 October, as seen in the comparison of potential temperatures (Fig. 3).

\section{b. Asymmetry of the flow}

The asymmetry of the foehn flow at "upper" levels of the Wipp Valley (levels above -1800 m MSL) was even stronger on 3 October than on 2 October (Fig. 16). At lower levels of the Wipp Valley the observed asymmetry was similar to the previous day. As on 2 October, the main reasons for the asymmetry at "lower" levels seem to be the inertia of the southerly flow forcing 

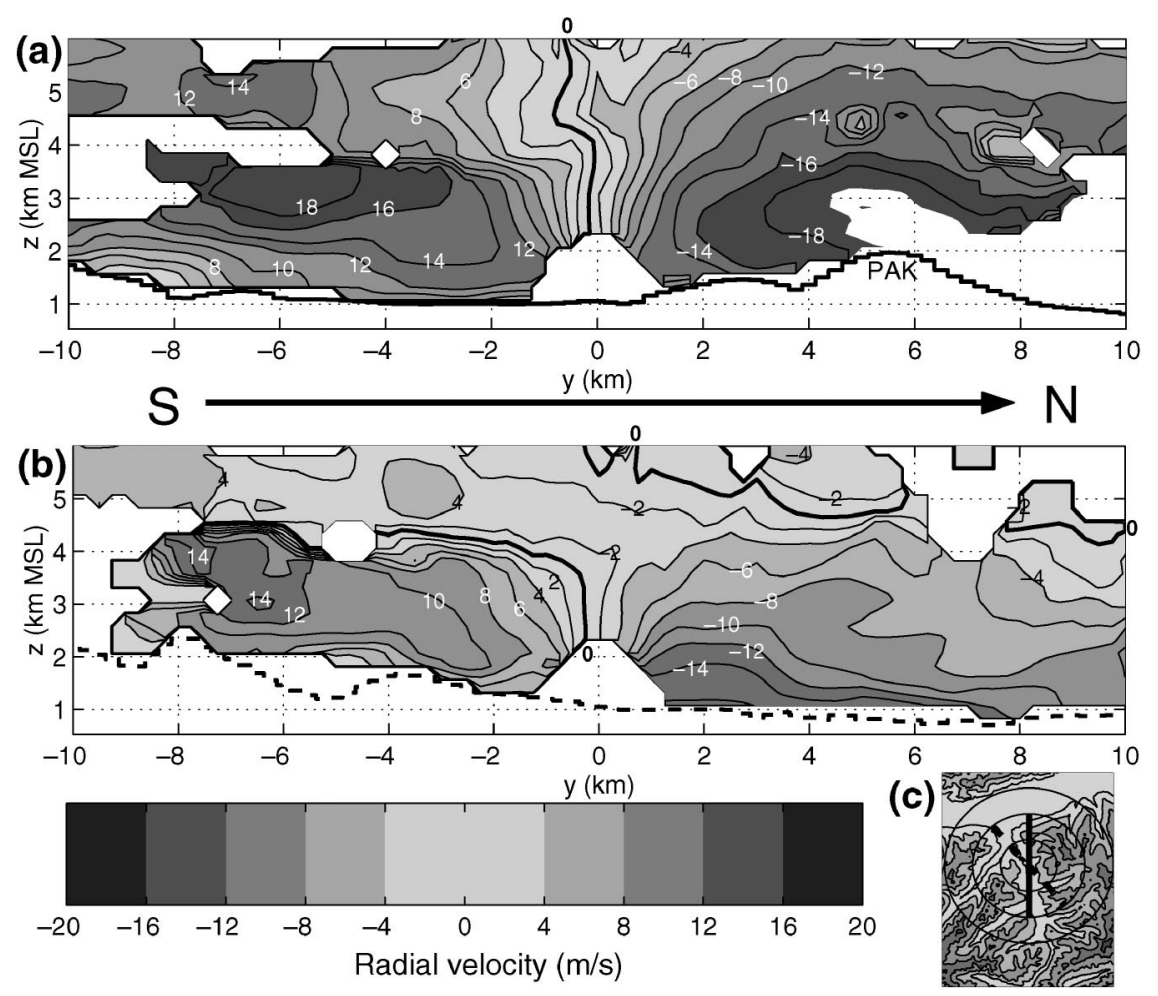

FIG. 16. Two vertical cross sections of radial velocity, each derived from one lidar scan. The scans were taken at 1103 UTC 3 Oct at an azimuth angle of (a) $0^{\circ}$ and (b) $320^{\circ}$. (c) The baseline of the scans is shown as (a) a solid black line and (b) a dashed black line. An arrow indicates the main direction of foehn flow. Positive radial velocities are flow toward the lidar, and negative velocities are flow away from the lidar.

against the turning of the Wipp Valley, and a hydraulic jump in the western part of the valley (see section $3 \mathrm{c}$ ). But at "upper" levels also the effect of midlevel winds may be important on 3 October. Midlevel winds were not separated from foehn flow by a temperature inversion, and the speeds between 4000 and $4500 \mathrm{~m}$ MSL were $20-30 \mathrm{~m} \mathrm{~s}^{-1}$, nearly twice as strong as on the previous day (Fig. 5). Presumably stronger southwesterly midlevel winds and the absence of an inversion lead to a stronger outflow of the Stubai Valley at levels above $1800 \mathrm{~m}$ MSL as described in section 3c. Unfortunately, it was not possible to quantify this outflow with the dataset of 3 October. But the fact that the asymmetry of the flow at "upper" levels was stronger on 3 October than on 2 October, and that a very strong asymmetry at "upper" levels was seen around 1600 UTC on 2 October, at the same time as midlevel winds showed a maximum (Fig. 5), suggests the importance of midlevel winds for the asymmetry at the "upper" levels of the Wipp Valley.

\section{Conclusions}

A comprehensive analysis of gap flow in the Wipp Valley on 2 and 3 October 1999 was performed from the extensive dataset of the Mesoscale Alpine Pro- gramme (MAP). This study describes the synoptic conditions leading to foehn, the temporal evolution of the flow, and the three-dimensional flow structure at and downstream of the gap.

Foehn flow (gap flow) in the Wipp Valley is caused by a pressure gradient across the Alps with higher pressure to the south. Atypically, the pressure gradient on 2 and 3 October was not caused by a temperature gradient across the Alps with cold air to the south, but rather by the large-scale pressure field with a wide trough over northern Europe.

It was one of the preliminary results of MAP that most of the foehn air does not flow through the lower, narrow notch directly above Brenner Pass, but through the wide, upper part of the gap between 2000 and 3100 m MSL (Mayr et al. 2004). The analysis of lidar and aircraft data of 2 and 3 October strongly confirms this.

To the north of the gap, some air descends to the lee of SAT (2108 m MSL), but most of the air stays elevated until the Wipp Valley widens north of NOS (2231 m MSL). This leads to a strong descent (shooting flow) to the lee of NOS and a jumplike feature $4 \mathrm{~km}$ downstream of NOS. Some lidar scans showed a flow reversal above the shooting flow, which was interpreted as a reversed rotor. Another, even stronger, flow reversal (reversed rotor) was seen to the lee of the mountain PAK, at the 
same location where an aerosol lidar and hydraulic simulations by Gohm and Mayr (2004) showed a hydraulic jump on 20 October 1999. Also, simulations using MM5 by Zängl et al. (2004) have shown a reversed rotor structure on 24 October 1999. But this study is the first to document the reversed rotor with Doppler lidar data.

The flow features to the lee of NOS (shooting flow, jumplike feature) only occurred during events with a strong near-crest-level inversion as on 30 (Flamant et al. 2002) and 20 October 1999 (Gohm and Mayr 2004). But they were not observed during deep foehn events as on 3 or 24 October 1999 (Gohm et al. 2004; Zängl et al. 2004).

A 500-m-deep jet layer formed in the Wipp Valley north of NOS. This layer was elevated about $500 \mathrm{~m}$ AGL in the southern part of the Wipp Valley and descended to the ground as it passed GED. Many lidar scans showed a wavy structure of the jet layer, which may be related to gravity waves.

In the northernmost part of the Wipp Valley, close to Innsbruck, wind speeds were nearly twice as high in the eastern half of the valley as in the western half. This leaning of the flow toward the eastern sidewall seemed to be caused by 1) the inertia forcing the flow against the westward turn of the Wipp Valley in this region, and 2) a hydraulic jump-like feature to the lee of WAL, as it was also shown in Gohm and Mayr (2004) and Gohm et al. (2004). The interaction with synoptic winds as described in Flamant et al. (2002) is seen to be negligible during shallow foehn events, which are decoupled from midlevel winds by a strong inversion as on 2 October 1999. It may have a small impact during deep foehn events as on 3 October.

The Alpine foehn is usually classified into two categories: shallow and deep. Foehn flow that does not extend above the main Alpine crest is a shallow foehn. If the foehn flow reaches higher, it is a deep one. During the foehn event of 2 through 3 October it was possible to observe the rise of the inversion above the average height of the main Alpine crest. This rise did not result in a change of the flow structure (section 3b). Only when the inversion dissolved during the night of 2 to 3 October did the flow structure change. This suggests that the existence of an inversion at the upper boundary of foehn flow as well as the depth of the foehn layer should be used to classify the foehn type.

Acknowledgments. The authors want to thank Louisa Nance, Lisa Darby, Johannes Vergeiner, and Andreas Schaffhauser for their valuable comments, fruitful discussions, and various technical support.

\section{REFERENCES}

Afanasyev, Ya. D., and W. R. Peltier, 2001a: On breaking internal waves over the sill in Knight Inlet. Proc. Roy. Soc. London, A457, 2799-2825.

- and - 2001b: Reply to comment on the paper "On breaking internal waves over the sill in Knight Inlet." Proc. Roy. Soc. London, A457, 2831-2834.

Armi, L., 1986: The hydraulics of two flowing layers with different densities. J. Fluid Mech., 163, 27-58.

Banta, R. M., L. D. Olivier, and J. M. Intrieri, 1990: Doppler lidar observations of the 9 January 1989 severe downslope windstorm in Boulder, Colorado. Preprints, Fifth Conf. on Mountain Meteorology, Boulder, CO, Amer. Meteor. Soc., 68-69.

, — - P. H. Gudiksen, and R. Lange, 1996: Implications of small-scale flow features to modeling dispersion over complex terrain. J. Appl. Meteor., 35, 330-342.

_- and Coauthors, 1997: Nocturnal cleansing flows in a tributary valley. Atmos. Environ., 31, 2147-2162.

— , L. S. Darby, P. Kaufman, D. H. Levinson, and C. J. Zhu, 1999: Wind flow patterns in the Grand Canyon as revealed by Doppler lidar. J. Appl. Meteor., 38, 1069-1083.

Bougeault, P., P. Binder, and C. Schär, 1998: MAP-Mesoscale Alpine Programme Science Plan, June 1998. SMA, 64 pp. [Available from SMA, Krähbühlstr. 58, CH-8044 Zurich, Switzerland, and online at http://www.map.ethz.ch/splan/spindex.htm.]

Clark, T. L., W. D. Hall, and R. M. Banta, 1994: Two- and threedimensional simulations of the 9 January 1989 windstorm: Comparison with observations. J. Atmos. Sci., 51, 2317-2343.

Colle, B. A., and C. F. Mass, 1998a: Windstorms along the western side of the Washington Cascade Mountains. Part I: A high-resolution observational and modeling study of the 12 February 1995 event. Mon. Wea. Rev., 126, 28-52.

_ , and —_, 1998b: Windstorms along the western side of the Washington Cascade Mountains. Part II: Characteristics of past events and three-dimensional idealized simulations. Mon. Wea. Rev., 126, 53-71.

Cummins, P. F., 2000: Stratified flow over topography: Time-dependent comparisons between model solutions and observations. Dyn. Atmos. Oceans, 33, 43-72.

Drobinski, P., J. Dusek, and C. Flamant, 2001: Diagnostics of hydraulic jump and gap flow in stratified flows over topography. Bound.-Layer Meteor., 98, 475-495.

Durran, D. R., and J. B. Klemp, 1987: Another look at downslope winds. Part II: Nonlinear amplification beneath wave-overturning layers. J. Atmos. Sci., 44, 3402-3412.

— - T. Maric, R. M. Banta, L. S. Darby, and R. M. Hardesty, 2003: A comparison of ground-based lidar and airborne in situ wind observations above complex terrain. Quart. J. Roy. Meteor. Soc., 129, 693-713.

Farmer, D., and L. Armi, 1999: Stratified flow over topography: The role of small-scale entrainment and mixing in flow establishment. Proc. Roy. Soc. London, 455, 3221-3258.

— observations. Proc. Roy. Soc. London, 457, 1-4.

Flamant, C., and Coauthors, 2002: Gap flow in Alpine valley during a shallow south foehn event: Observations, numerical simulations and hydraulic analog. Quart. J. Roy. Meteor. Soc., 128, $1173-1210$.

Gohm, A., and G. J. Mayr, 2004: Hydraulic aspects of foehn winds in an Alpine valley. Quart. J. Roy. Meteor. Soc., 130, 449-480.

— , G. Zängl, and G. J. Mayr, 2004: South foehn in the Wipp Valley on 24 October 1999 (MAP IOP 10): Verification of high-resolution numerical simulations with observations. Mon. Wea. Rev., 132, 78-102.

Houghton, D. D., and A. Kasahara, 1968: Nonlinear shallow fluid flow over an isolated ridge. Commun. Pure Appl. Math., 21, 123.

Klemp, J. B., and D. K. Lilly, 1975: The dynamics of wave-induced downslope winds. J. Atmos. Sci., 32, 320-339.

Long, R. R., 1954: Some aspects of the flow of stratified fluids. II. Experiments with a two-fluid system. Tellus, 6, 97-115.

Malcher, P., 2001: Case studies of turbulence and vertical motion experienced by research aircraft during MAP SOP south foehn cases. M.S. thesis, Dept. of Meteorology, University of Innsbruck 
93 pp. [Available online at http://www2.uibk.ac.at/fakultaeten/ c7/c707/theses/diplomatheses/.]

Mayr, G. J., J. Vergeiner, and A. Gohm, 2002: An automobile platform for the measurement of foehn and gap flows. J. Atmos. Oceanic Technol., 19, 1545-1556.

— I. I. Vergeiner, A. Gohm, J. Vergeiner, and R. Mayr, 2003: Gap flow-An overview and preliminary results. Öster Beitr. Meteor. Geophys., 29, 15-54. [Available from Zentralanstalt für Meteorologie und Geodynamik, A-1190 Vienna, Austria.]

— and Coauthors, 2004: Gap flow measurements during the Mesoscale Alpine Programme. Meteor. Atmos. Phys., 86, 99-119.

Pan, F., and R. B. Smith, 1999: Gap winds and wakes: SAR observations and numerical simulations. J. Atmos. Sci., 56, 905-923.

Pawlak, G., and L. Armi, 1998: Vortex dynamics in a spatially accelerating shear layer. J. Fluid Mech., 376, 1-35.

Pielke, R. A., Sr., 2002: Mesoscale Meteorological Modeling. 2d ed. Academic Press, $676 \mathrm{pp}$.

Post, M. J., and R. E. Cupp, 1990: Optimizing a pulsed Doppler lidar. Appl. Opt., 29, 4145-4158.

Rotunno, R., and P. K. Smolarkiewicz, 1995: Vorticity generation in the shallow-water equations as applied to hydraulic jumps. $J$. Atmos. Sci., 52, 320-330.
Rouse, H., T. T. Siao, and S. Nagaratnam, 1959: Turbulence characteristics of the hydraulic jump. Trans. Amer. Soc. Civ. Eng., 124, 926-966.

Seibert, P., 1990: South foehn studies since the ALPEX experiment. Meteor. Atmos. Phys., 43, 91-103.

Smith, R. B., 1985: On severe downslope winds. J. Atmos. Sci., 42, 2597-2603.

Sprenger, M., and C. Schär, 2001: Rotational aspects of stratified gap flows and shallow foehn. Quart. J. Roy. Meteor. Soc., 127, 161187.

Weissmann, M., 2003: Temporal evolution and structure of foehn in the Wipp Valley on 2 and 3 October 1999. M.S. thesis, Dept. of Meteorology, University of Innsbruck, $84 \mathrm{pp}$. [Available online at http://www2.uibk.ac.at/fakultaeten/c7/c707/theses/diplomatheses/.]

WMO, 1992: International Meteorological Dictionary. World Meteorological Organization, $784 \mathrm{pp}$.

Wood, I. R., 1968: Selective withdrawal from a stably stratified fluid. J. Fluid Mech., 32, 209-223.

Zängl, G., A. Gohm, and G. Geier, 2004: South foehn in the Wipp Valley-Innsbruck region: Numerical simulations of the 24 October 1999 case (MAP-IOP 10). Meteor. Atmos. Phys., 86, 213 243. 